\title{
Community-based bilingual doulas for migrant women in labour and birth - findings from a Swedish register-based cohort study
}

\author{
Ulrika Byrskog ${ }^{1 *}$, Rhonda Small ${ }^{2,3}$ and Erica Schytt $3,4,5$
}

\begin{abstract}
Background: Community-based bilingual doula (CBD) services have been established to respond to migrant women's needs and reduce barriers to high quality maternity care. The aim of this study was to compare birth outcomes for migrant women who received CBD support in labour with birth outcomes for (1) migrant women who experienced usual care without CBD support, and (2) Swedish-born women giving birth during the same time period and at the same hospitals.

Methods: Register study based on data retrieved from a local CBD register in Gothenburg, the Swedish Medical Birth Register and Statistics Sweden. Birth outcomes for migrant women with CBD support were compared with those of migrant women without CBD support and with Swedish-born women. Associations were investigated using multivariable logistic regression, reported as odds ratios (aORs) with 95\% confidence intervals (Cl), adjusted for birth year, maternal age, marital status, hypertension, diabetes, BMI, disposable income and education.

Results: Migrant women with CBD support $(n=880)$ were more likely to have risk factors for adverse pregnancy outcomes than migrant women not receiving CBD support $(n=16,789)$ and the Swedish-born women $(n=129$, 706). In migrant women, CBD support was associated with less use of pain relief in nulliparous women (epidural aOR 0.64, Cl 0.50-0.81; bath aOR 0.64, Cl 0.42-0.98), and in parous women with increased odds of induction of labour (aOR 1.38, Cl 1.08-1.76) and longer hospital stay after birth (aOR 1.19, Cl 1.03-1.37). CBD support was not associated with non-instrumental births, perineal injury or low Apgar score. Compared with Swedish-born women, migrant women with CBD used less pain relief (nulliparous women: epidural aOR 0.50, Cl 0.39-0.64; nitrous oxide aOR 0.71, Cl 0.54-0.92; bath aOR 0.55, Cl 0.36-0.85; parous women: nitrous oxide aOR 0.68, Cl 0.54-0.84) and nulliparous women with CBD support had increased odds of emergency caesarean section (aOR 1.43, Cl 1.05-1.94) and longer hospital stay after birth (aOR 1.31, Cl 1.04-1.64).
\end{abstract}

Conclusions: CBD support appears to have potential to reduce analgesia use in migrant women with vulnerability to adverse outcomes. Further studies of effects of CBD support on mode of birth and other obstetric outcomes and women's experiences and well-being are needed.

Keywords: Community-based bilingual doula support, register study, labour and birth outcomes, migrant

\footnotetext{
* Correspondence: uby@du.se

'School of Education, Health and Social Sciences, Dalarna University, Falun, Sweden

Full list of author information is available at the end of the article
}

(c) The Author(s). 2020 Open Access This article is licensed under a Creative Commons Attribution 4.0 International License, which permits use, sharing, adaptation, distribution and reproduction in any medium or format, as long as you give appropriate credit to the original author(s) and the source, provide a link to the Creative Commons licence, and indicate if changes were made. The images or other third party material in this article are included in the article's Creative Commons licence, unless indicated otherwise in a credit line to the material. If material is not included in the article's Creative Commons licence and your intended use is not permitted by statutory regulation or exceeds the permitted use, you will need to obtain permission directly from the copyright holder. To view a copy of this licence, visit http://creativecommons.org/licenses/by/4.0/. The Creative Commons Public Domain Dedication waiver (http://creativecommons.org/publicdomain/zero/1.0/) applies to the data made available in this article, unless otherwise stated in a credit line to the data. 


\section{Background}

The introduction of community-based bilingual doulas (CBDs) is one initiative that aims to respond to migrant women's needs and to reduce barriers to high quality maternity care $[1,2]$. Migrant women's increased risk of adverse pregnancy outcomes and some obstetric interventions such as caesarean section, is well-known [3-6]. Migrant women have also rated maternity care less positively than non-migrant women and may experience communication and language barriers, lack of familiarity with how care is provided, and discrimination and negative staff attitudes. Experiences of being left alone in labour, and feeling fearful, unsafe and unsupported have also been reported by migrant women [1].

CBDs are lay women from migrant communities, fluent in both the destination country language and the mother tongue of the pregnant migrant woman, trained to provide continuous empowering and woman-focused support that complements the role of midwives. The CBD's language and cultural understanding facilitates communication between the woman-partner-staff during labour and birth, even though she does not replace an accredited interpreter, and helps women and their partners in navigating an unfamiliar maternity care system [7-11]. To date, results from randomised controlled trials of $\mathrm{CBD}$ during childbirth for migrant women have not yet been reported. Observational studies suggest that CBD support increases migrant women's probability of a normal labour and birth [8,9], and increased breastfeeding initiation [12]. A positive experience of care has been reported [10,13,14], also after a cesarean [15], and no harms have been documented [12, 13, 16]. In addition, continuous physical and emotional support in labour from a person assigned only to provide support, such as a doula, is associated with less use of analgesia [17], even though some studies have shown no differences in analgesia use $[9,18]$.

The CBD project in Gothenburg, Sweden, was established in 2008 by the community association, Födelsehuset/Mammaforum ('Childbirth House/Mother Forum') and has since provided CBDs during labour and birth for language assistance and support to migrant women not fluent in Swedish. Bilingual women from migrant communities trained in childbirth and labour support meet once or twice with women prior to the birth, provide a continuous presence and emotional and physical support as well as communication assistance during labour, and meet again with the women after the birth. Two qualitative evaluations, conducted in the early years of the program, indicated high levels of satisfaction among supported women [19] and midwives [20]. Improved communication and information-sharing and enhanced emotional and physical support were the most important outcomes reported. Since then around 1,400 women have received
CBD support, however, the program has not yet been evaluated for its impact on birth outcomes. The current study fills an important gap in knowledge about the CBD model and complements an ongoing RCT of CBD support in Stockholm, Sweden - where the objective is to study women's experiences of care and their emotional wellbeing [2] - by evaluating an already successfully implemented pragmatic model using a sufficient sample size for important labour and birth outcomes.

In Sweden, care during pregnancy, labour and birth is offered free of charge to all women. Less than one percent of all births take place outside hospitals. Registered midwives are the primary caregivers during normal labour and birth and where complications arise, an obstetrician will be consulted and/or assume responsibility for the care provided [21]. Care is regulated by national, regional and local guidelines and a midwife may care for one to four women in labour at the same time. Access to a language interpreter is mandated by Swedish law but the routines for language interpretation during labour and birth differ between hospitals and the use of tele-phone interpretation is most common. Interpreters are also most often provided on specific occasions when deemed necessary by staff, for instance to explain a procedure or change in the care strategy and not as a continuous means of communication support.

Migration of women of childbearing age (13-44 years) has increased most rapidly in Sweden from Somalia and from a number of Arabic-speaking countries (such as Iraq or Syria) and Eritrea [22]. Other migrant groups who have arrived in Sweden over the last decade include women from Central and Eastern Europe, as well as Central and South and East Asia [23]. Knowledge of the Swedish maternity care system, length of time in Sweden and fluency in Swedish vary between individuals and groups and communication difficulties when accessing care are also experienced to varying extents.

The aim of the current study was to compare birth outcomes for migrant women who received CBD support in labour, with birth outcomes for [1] migrant women who experienced usual care without CBD support, and [2] Swedishborn women giving birth during the same time period at the same hospitals. We hypothesised [1] that migrant women who received CBD support would use less analgesia and would have more non-instrumental vaginal births than migrant women who received usual intrapartum care without CBD support; and [2] that migrant women who received CBD support would not differ from Swedish-born women regarding analgesia use and mode of birth.

\section{Methods}

Design

This retrospective cohort study investigated data retrieved from a local register held by Mammaforum/ 
Födelsehuset in Gothenburg [24], and from two national registers: the Swedish Medical Birth register (MBR) [25] and Statistics Sweden [26] linked by each woman's unique national identity number.The exposure of interest was CBD support and a range of obstetric outcomes of interest were investigated, as outlined below.

The MBR is based on mandatory notification of data from the medical records for all births in Sweden, and includes information on women's obstetric background, maternal health before and during pregnancy, current pregnancy, labour and birth, and maternal and infant outcomes. The register was initiated in 1973, covers 99\% of all births and the quality and validity of included data have been evaluated at three time points $[27,28]$. Statistics Sweden produces and coordinates official statistics according to international standards for research [29] and provided information on migration and socioeconomic factors.

\section{Study setting and sample}

Through Födelsehuset/Mammaforum ('Childbirth House/Mother Forum') in Gothenburg, women not fluent in Swedish were offered support by a CBD, bilingual in Swedish and the woman's own language and well acquainted with the cultures of both countries. The ages of the CBDs ranged between 30 and 65 years and all had attended 8 days of certified training conducted by registered midwives with specific accreditation for CBD training. The course included basic anatomy, normal pregnancy and birth, relaxation techniques, pain relief, medical interventions, instrumental delivery, breast feeding, attachment and the newborn baby. Information about the CBD service was provided either when women participated in other activities organized by the community association or via a referral from the woman's regular antenatal care midwife.

The study sample included births to (1) migrant women who had received CBD during the period between 2008 and 2016, and for comparison, (2) migrant women from the same countries and who had given birth in the same hospitals during the study period but did not have support from a CBD during labour and birth and (3) all Swedish-born women who gave birth in the same hospitals during the same time-period as the migrant women. Births to migrant women with $\mathrm{CBD}$ support were identified through personal identification numbers available in a register kept by Födelsehuset/ Mammaforum. After exclusion of births with incomplete personal ID, missing data on year and date of birth, and spontaneous or induced abortions, the file comprising migrant women with CBD support was sent to MFR and SCB for linkage to register data. Duplicates or no matching births in the MFR/SCB registers were excluded, the data were de-identified and matching births for the two comparison groups were identified and added to the data set (Fig. 1). For estimation of representativeness, data on maternal age, marital status, country of birth, BMI, smoking and parity for all births in Sweden during the time-period were also obtained.

\section{Exposure}

CBD support for labour and birth was defined as being assigned to receive $\mathrm{CBD}$ support as reported in the register at Födelsehuset/Mammaforum. The CBD service included one to two preparatory meetings before the birth during which the doula and woman or couple could get acquainted with each other and the woman's expectations and wishes for the coming birth could be shared, in addition to knowledge transfer about the birthing process and care during labour and birth in Sweden. During labour and birth the CBD provided continuous presence, emotional and physical and supported communication between the woman and the staff. The follow up visit after birth included reflections regarding the birthing experience, support in breast feeding and attachment, and information support as needed about Swedish social and other services.

\section{Outcomes}

Outcome variables were retrieved from the MBR and included the following: induction of labour, use of epidural analgesia, nitrous oxide, bath, non-instrumental vaginal delivery, instrumental vaginal delivery (vacuum extraction and forceps), emergency caesarean, third or fourth degree perineal injury, length of mother's hospital stay after the birth $>2$ days and low Apgar score $<7$ at five minutes.

\section{Other variables of interest}

From Statistics Sweden we retrieved the following variables specifically for the year of the baby's birth: maternal level of education (not completed compulsory school, compulsory school (9 years), upper secondary school (11-12 years), post-secondary education) and disposable income categorized into percentiles $\leq 25,26-75$, and $\geq 75$ based on the household income per unit of consumption for all women giving birth in Sweden that year. Migration related variables retrieved from Statistics Sweden were maternal country of birth classified into region of birth, modified from Global Burden of Diseases (Sub-Saharan Africa, North Africa \& Middle East, Central Europe, Eastern Europe \& Central Asia, South \& East Asia \& Oceania, other) [30], reason for migration (work/education, refugee, family reunion, other) and length of residence in Sweden $(<2,2-56-9, \geq 10$ years). From the MBR we retrieved the following variables: maternal age $(<25,25-34, \geq 35$ years), marital status (mar$\mathrm{ried} /$ cohabiting, single, other), previous cesarean section, 


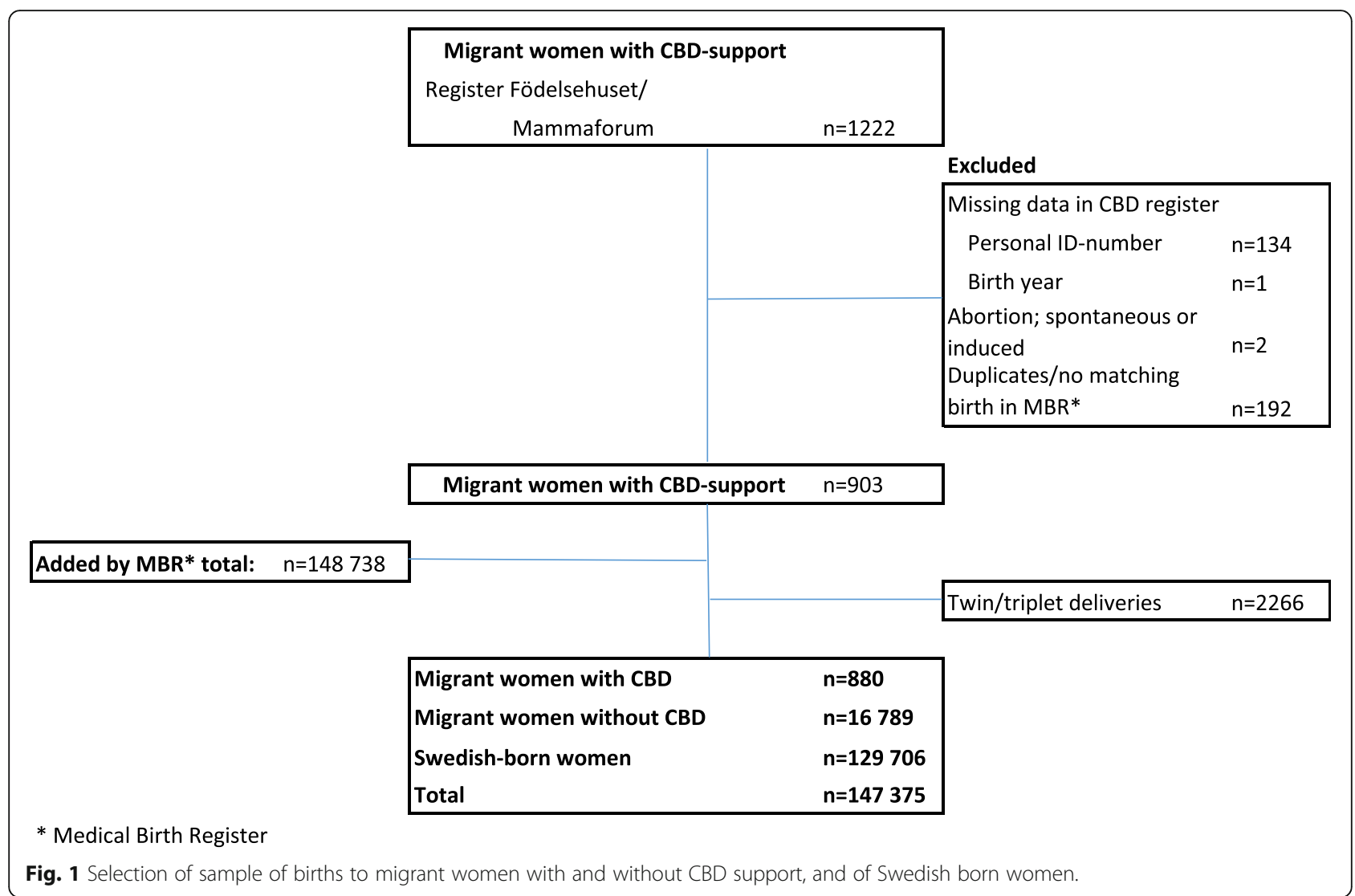

previous stillbirth, year of the current birth, parity (nulliparous, parous), smoking in early pregnancy, chronic hypertension, diabetes (diabetes mellitus type one, two, or gestational diabetes), preeclampsia/eclampsia, prepregnancy body mass index (BMI) (underweight; < $18.5 \mathrm{~kg}$, normal weight (18.5-24.9 kg), overweight (25.0$29.9 \mathrm{~kg}$,obesity; $\geq 30)$, number of antenatal visits $(<8,8-$ $12,>12)$, gestational weeks (gwks) at birth $(<37,37-41$, $\geq 42$ ) and birthweight ( $\leq 2500,2501-4500>4500$ grams).

\section{Statistical analyses}

Univariate and multivariable logistic regression analyses were used to investigate possible associations between CBD support and birth outcomes and are reported as crude and adjusted odds ratios (ORs) with 95\% confidence intervals (CIs). For transparency and to facilitate interpretation, adjustments were made in three steps. In the first model we adjusted for year of the current birth due to the long time span of the study (8 years), maternal age and marital status. In the second model we adjusted for the same variables and added hypertension, diabetes and BMI and in the third model, adjustments for disposable income and education were added. Missing values were considered not missing at random and analysed as a separate category so as not to lose cases in the final models. For the categorical variables used in the models; age, marital status, the first category (Table 1) was set as the reference. Analyses were conducted for nulliparous and multiparous women separately. Birth outcomes were also compared between migrant women with CBD support and Swedish-born women using the same strategy. In order to identify potential associations with CBD support in any particular groups of women, stratified analyses were performed in the following sub-groups: refugee background, SubSaharan or Middle East and North Africa (the largest groups) and length of residence in Sweden less than two years. All statistical analyses were performed using IBM Statistical Package for the Social Sciences 26.

\section{Results}

The final sample comprised 880 births to migrant women who had a CBD for labour and birth, 16,789 births to migrant women without a CBD present and 129,706 births to Swedish-born women; in total 147,375 births after the exclusion of those with incomplete data, spontaneous or induced abortion, births recorded twice, no matching birth in the MFR and twin or triplet births (Fig. 1).

Background characteristics of the study sample are shown in Table 1. Compared with both comparison groups, migrant women who had CBD support were: younger and more likely to be single, they had lower 
Table 1 Background characteristics of the sample $(n=147,375)$

\begin{tabular}{|c|c|c|c|c|c|c|c|c|}
\hline & \multicolumn{4}{|c|}{ Migrant women } & \multirow[b]{3}{*}{$p^{a}$} & \multirow{2}{*}{\multicolumn{2}{|c|}{$\begin{array}{l}\text { Swedish-borr } \\
(n=129, \\
706)\end{array}$}} & \multirow[t]{3}{*}{ n women } \\
\hline & \multicolumn{2}{|c|}{$\begin{array}{l}\text { CBD support }(n= \\
\mathbf{8 8 0})\end{array}$} & \multicolumn{2}{|c|}{$\begin{array}{l}\text { No CBD support ( } n=16 \text {, } \\
789 \text { ) }\end{array}$} & & & & \\
\hline & $\mathbf{n}$ & $\%$ & $\mathbf{n}$ & $\%$ & & $\mathbf{n}$ & $\%$ & \\
\hline \multicolumn{9}{|l|}{ Socioeconomic background } \\
\hline Age (years) & & & & & $<0.0001$ & & & $<0.0001$ \\
\hline$<25$ & 213 & 24.2 & 2829 & 16.9 & & 15,757 & 12.1 & \\
\hline $25-34$ & 520 & 59.1 & 10,319 & 61.5 & & 85,585 & 66.0 & \\
\hline$\geq 35$ & 147 & 16.7 & 3641 & 21.7 & & 28,364 & 21.9 & \\
\hline Marital status & & & & & $<0.0001$ & & & $<0.0001$ \\
\hline Married/cohabiting & 621 & 71.6 & 14,251 & 87.4 & & 115,804 & 94.4 & \\
\hline Single & 91 & 10.5 & 751 & 4.6 & & 2169 & 1.8 & \\
\hline Other & 155 & 17.9 & 1302 & 8 & & 4756 & 3.9 & \\
\hline Level of education & & & & & $<0.0001$ & & & $<0.0001$ \\
\hline Not completed compulsory schooling ${ }^{\mathrm{b}}$ (<9 years) & 255 & 37.4 & 2696 & 17.6 & & 245 & 0.2 & \\
\hline Compulsory schooling (9 years) & 101 & 14.8 & 1761 & 11.5 & & 8317 & 6.4 & \\
\hline Upper secondary school (11-12 years) & 143 & 21.0 & 4910 & 32.1 & & 46,135 & 35.7 & \\
\hline Post-secondary education (vocational qualification \& university) & 183 & 26.8 & 5943 & 38.8 & & 74,617 & 57.7 & \\
\hline Mother's income & & & & & $<0.0001$ & & & $<0.0001$ \\
\hline$\leq 25$ percentile & 754 & 89.5 & 10,369 & 63.2 & & 25,687 & 19.8 & \\
\hline 25-75 percentile & 82 & 9.7 & 4922 & 29.4 & & 68,547 & 52.9 & \\
\hline$\geq 75$ percentile & 6 & 0.7 & 1461 & 8.7 & & 35,362 & 27.3 & \\
\hline \multicolumn{9}{|l|}{ Migration } \\
\hline Region of birth & & & & & $<0.0001$ & & & \\
\hline Sub-Saharan Africa & 392 & 44.6 & 3595 & 21.4 & & & & \\
\hline North Africa \& Middle East & 396 & 45.1 & 8348 & 49.7 & & & & \\
\hline Central Europe Eastern Europe \& Central Asia & 76 & 8.6 & 3283 & 19.6 & & & & \\
\hline South and East Asia \& Oceania & 10 & 1.1 & 1241 & 7.4 & & & & \\
\hline Other & 5 & 0.6 & 322 & 1.9 & & & & \\
\hline Reason for immigration & & & & & $<0.0001$ & & & \\
\hline Work/education & 14 & 1.7 & 325 & 2.1 & & & & \\
\hline Refugee & 301 & 36.4 & 4817 & 30.9 & & & & \\
\hline Family reunion & 472 & 57.1 & 8215 & 52.7 & & & & \\
\hline Other & 39 & 4.7 & 2241 & 14.4 & & & & \\
\hline Length of Residence & & & & & $<0.0001$ & & & \\
\hline$<2$ years & 347 & 41.2 & 2966 & 17.7 & & & & \\
\hline $2-5$ years & 319 & 37.9 & 3741 & 22.3 & & & & \\
\hline $6-9$ years & 139 & 16.5 & 3186 & 19.0 & & & & \\
\hline$\geq 10$ years & 37 & 4.4 & 6885 & 41.0 & & & & \\
\hline \multicolumn{9}{|l|}{ Obstetric history } \\
\hline Previous caesarean section & 98 & 12.9 & 1872 & 11.7 & 0.287 & 11,221 & 8.7 & $<0.0001$ \\
\hline Previous stillbirth & 21 & 2.4 & 260 & 1.5 & 0.053 & 805 & 0.6 & $<0.0001$ \\
\hline \multicolumn{9}{|l|}{ Present pregnancy } \\
\hline Parity & & & & & $<0.05$ & & & $<0.05$ \\
\hline Nulliparous & 379 & 43.1 & 6440 & 38.4 & & 61,459 & 47.4 & \\
\hline Parous & 500 & 56.9 & 10,349 & 61.6 & & 68,247 & 52.6 & \\
\hline
\end{tabular}


Table 1 Background characteristics of the sample $(n=147,375)$ (Continued)

\begin{tabular}{|c|c|c|c|c|c|c|c|c|}
\hline & \multicolumn{4}{|c|}{ Migrant women } & \multirow[b]{3}{*}{$p^{a}$} & \multirow{2}{*}{\multicolumn{3}{|c|}{$\begin{array}{l}\text { Swedish-born women } \\
(n=129, \\
706)\end{array}$}} \\
\hline & \multicolumn{2}{|c|}{$\begin{array}{l}\text { CBD support }(n= \\
880)\end{array}$} & \multicolumn{2}{|c|}{$\begin{array}{l}\text { No CBD support }(n=16 \text {, } \\
\text { 789) }\end{array}$} & & & & \\
\hline & $\mathrm{n}$ & $\%$ & $\mathrm{n}$ & $\%$ & & $n$ & $\%$ & $p^{a}$ \\
\hline Smoking in early pregnancy & 19 & 2.2 & 906 & 5.6 & $<0.0001$ & 7583 & 6.2 & $<0.0001$ \\
\hline Chronic hypertension & 0 & 0 & 41 & 0.2 & 0.142 & 516 & 0.4 & 0.061 \\
\hline Diabetes Mellitus type 1 or 2 & 3 & 0.3 & 72 & 0.4 & 0.696 & 884 & 0.7 & 0.220 \\
\hline Gestational diabetes & 12 & 1.4 & 414 & 2.5 & $<0.05$ & 1104 & 0.9 & 0.100 \\
\hline Pre-eclampsia/eclampsia & 18 & 2.0 & 418 & 2.5 & 0.408 & 4059 & 3.1 & 0.065 \\
\hline Pre-pregnancy BMI (kg/m²) & & & & & $<0.0001$ & & & $<0.0001$ \\
\hline Underweight $(<18.5)$ & 24 & 2.9 & 425 & 2.8 & & 2354 & 2 & \\
\hline Normal weight (18.5-24.9) & 353 & 42.6 & 7904 & 51.5 & & 73,085 & 62.6 & \\
\hline Overweight (25.0-29.9) & 268 & 32.3 & 4676 & 30.5 & & 27,953 & 24 & \\
\hline Obesity ( $\geq 30)$ & 184 & 22.2 & 2334 & 15.2 & & 13,317 & 11.4 & \\
\hline Antenatal care visits (No) & & & & & $<0.001$ & & & $<0.0001$ \\
\hline$<8$ & 115 & 13.2 & 2963 & 18.1 & & 21,997 & 17.0 & \\
\hline $8-12$ & 544 & 62.7 & 10,132 & 62 & & 82,289 & 66.6 & \\
\hline$>12$ & 209 & 24.1 & 3258 & 19.9 & & 19,334 & 15.6 & \\
\hline Gestational weeks (gwks) & & & & & $<0.0001$ & & & $<0.0001$ \\
\hline Preterm < 37 & 19 & 2.2 & 942 & 5.6 & & 7278 & 5.6 & \\
\hline Term 37-41 & 714 & 81.1 & 14,433 & 86.0 & & 112,678 & 86.9 & \\
\hline Post-term $\geq 42$ & 147 & 16.7 & 1410 & 8.4 & & 9740 & 7.5 & \\
\hline Birth weight, (grams) & & & & & $<0.05$ & & & 0.013 \\
\hline$\leq 2500$ & 26 & 3.0 & 888 & 5.3 & & 4865 & 3.8 & \\
\hline $2501-4500$ & 834 & 94.8 & 15,566 & 92.8 & & 119,528 & 92.2 & \\
\hline$>4500$ & 20 & 2.3 & 319 & 1.9 & & 5210 & 4.0 & \\
\hline
\end{tabular}

${ }^{\mathrm{a}}$ Differences between migrant women with $\mathrm{CBD}$ analysed

${ }^{\mathrm{b}}$ According to the Swedish educational system

'Based on categorisation by Global Burden of Diseases

level of education and lower disposable income, they had higher rates of previous stillbirths, overweight and obesity, more were nulliparous, had more antenatal care visits than the recommended standard and fewer gave birth at term. Smoking was less common however, than among women in the comparison groups. Compared with migrant women without CBD support, those with CBD support were more likely to have sub-Saharan African origin, to be refugees or to having migrated for family reunion, and they had shorter duration of residence in Sweden. Chronic hypertension, diabetes type 1 and 2 and preeclampsia/eclampsia were similar in all three groups. The study sample was fairly similar to all births in Sweden during the same time period (the study sample excluded), but comprised a somewhat higher proportion of nulliparous women ( $45.6 \%$ vs. $43.1 \%, \mathrm{p}<0.0001)$, women of normal-weight $(61.4 \%$ vs. $58.8 \%, \mathrm{p}<0.0001)$, and Swedish-born women $(88.0 \%$ vs. $71.0 \%, \mathrm{p}<0.0001)$. The extent of missing background data varied between the respective groups and between variables, ranging from $0.1 \%$ to $14 \%$, with level of education varying even more (22.5\%).

Associations between CBD support and labour, birth and infant outcomes in births to migrant women are shown in Table 2. Following adjustments, nulliparous migrant women with CBD support had decreased odds of having an epidural (aOR 0.64, CI 0.50-0.81) or of using a bath (aOR 0.64, CI 0.42-0.98) for labour pain compared with migrant women without such support. Parous migrant women supported by a CBD had increased odds of induction of labour (aOR 1.38, CI 1.081.76) and a hospital stay of more than 48 hours after the birth (aOR 1.19, CI 1.03-1.37) compared with migrant women without a CBD. No significant differences were found between the groups on the use of nitrous oxide, mode of birth, 3rd and 4th degree perineal injury, or low Apgar score at 5 minutes, either in primiparous or multiparous migrant women.

Associations between CBD support and birth outcomes were also investigated in sub-groups of migrant 
Table 2 Associations with labour and birth outcomes in nulliparous and parous migrant women with and without CBD support.

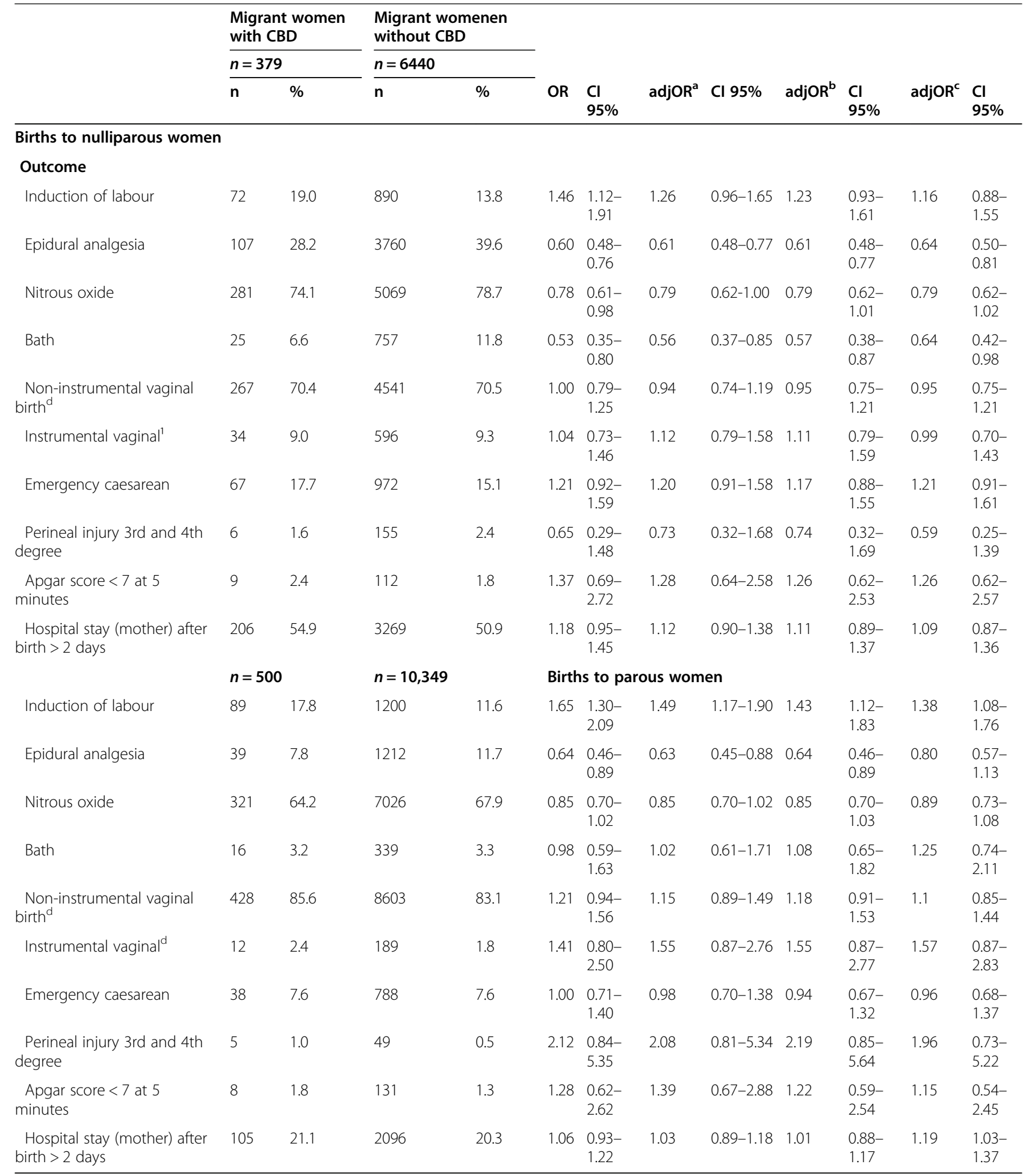

${ }^{a}$ Adjusted for year of birth, maternal age, marital status ${ }^{b}$ Adjusted for ${ }^{a}$ and hypertension, diabetes and BMI ${ }^{c}$ Adjusted for ${ }^{a}$ and ${ }^{b}$ and education and income

${ }^{1}$ Comparison group is instrumental vaginal and emergency caesarean births

women, nulliparous and parous women combined (data not shown). CBD support was associated with increased odds of induction of labour in women from Sub-Saharan Africa (CBD support 25.3\% ( $n=99)$; without CBD 18.7\%
( $n=673)$; aOR 1.38, CI 1.07-1.77), lower use of nitrous oxide in women from the Middle East and North Africa (CBD support 66.7\% $(n=264)$; without CBD 71.6\% $(\mathrm{n}=$ 5976); aOR 0.79, CI 0.63-0.99), lower use of epidural 
(CBD 19.6\% ( $n=68)$; without CBD 29.1\% $(n=862)$; aOR 0.69 , CI $0.52-0.92$ ) and nitrous oxide (CBD support $64.8 \%(n=225)$; without CBD $73.4 \%(\mathrm{n}=2177)$; aOR 0.78 , CI 0.61-0.99) in women with short residence in Sweden $(<2$ years).

Birth outcomes for migrant women who received CBD support were also compared with those of the Swedishborn women (Table 3). Both nulliparous and parous migrant women with CBD support had lower odds for having an epidural (aOR 0.50, CI 0.39-0.64 and aOR 0.40, CI $0.28-0.58$ ) or using nitrous oxide (aOR 0.71, CI 0.54-0.92 and aOR 0.68, CI 0.54-0.84), Nulliparous women with CBD support also had lower odds of using a bath for pain relief ( $\mathrm{aOR} 0.55$, CI 0.36-0.85), higher odds of an emergency caesarean (aOR 1.43, CI 1.051.94) and of a maternal hospital stay $>48$ hours (aOR 1.31, CI 1.04-1.64) than the Swedish-born women. The odds for 3rd and 4th degree perineal injury and low Apgar score were similar between the groups.

\section{Discussion}

Migrant nulliparous women and those with short length of residence who received labour and birth support from a CBD used less epidural analgesia and were less likely to use a bath for pain relief, compared with migrant women without such support. The support from a CBD did not however increase migrant women's probability of a non-instrumental vaginal birth. Compared with Swedish-born women, nulliparous migrant women supported by a CBD, were more likely to have an emergency caesarean, longer hospital stays and to have lower odds of pain relief during labour.

\section{Strengths and limitations}

This is the first register study to investigate the associations between CBD support for migrant women and a number of labour and birth outcomes in a multicultural setting. Linking data over a nine year period of CBD implementation with high quality national registers made it possible to include a sufficient number of CBDsupported women to compare their outcomes with the outcomes both for migrant women without such support and with Swedish-born women giving birth in the same hospitals during the same time period. Limited numbers in some sub-group analyses meant that instrumental vaginal births could not be analysed for refugee women separately, which is a limitation. A register study design enabled a focus on routinely collected obstetric outcomes. Although the wellbeing of women and their experiences of labour care and support are important, this study was unable to investigate these outcomes. The aforementioned ongoing RCT was designed to address these experiential outcomes.
We cannot dismiss the possibility of residual confounding although we strived to adjust for relevant confounding factors where possible. In addition, bearing in mind the differences in parity, BMI and language groups between the study sample and all births in Sweden during the same time period, the study findings cannot be generalized to the whole population or to immigrants in Sweden as a whole.

\section{Interpretation}

Notably, the results must be interpreted bearing in mind the selection of women for CBD support in labour and birth evident in this study. Our findings confirm that the CBD services had reached the women intended, in terms of their more vulnerable socioeconomic circumstances and migration related factors such as recent arrival, and/ or their increased risks of adverse birth outcomes and experiences.

The finding of an overall lower use of analgesia among the migrant women supported by a CBD, compared to migrant women without CBD services, confirms one of our study hypotheses. The finding could be viewed from two perspectives. Interpreted in light of systematic reviews by Hodnett et al. [31] and Bohren et al. [17] showing that continuous support for women during childbirth contributes to lower analgesia use, our findings may indicate a positive impact of the presence of a CBD and that women actually did not need an epidural. With a CBD present for continuous support, providing calmness and safety and improved communication during labour and birth, the prerequisites for women to manage labour pain and freely choose pain relief have most likely improved, and choices to abstain from pain relief may be more well-grounded. In comparison with Swedish-born women, the migrant women with CBD support also used less pain relief. This may, in the same way, be associated with the continuous presence of the CBD, indicating that even Swedish-born women would benefit from enhanced continuous support during labour and birth. On the other hand, our findings might be interpreted as evidence that migrant women miss out on available pain relief $[32,33]$. In line with the latter interpretation, two recent Norwegian register-based studies found lower use of epidural analgesia among women with similar characteristics as many of those receiving CBD support in our study, namely refugees, newly arrived women and women of Sub-Saharan origin [34, 35]. Qualitative studies conducted with migrant women themselves may be able to achieve more in-depth and nuanced perspectives on the role of CBD support for the adequacy of pain relief.

The hypothesis that CBD support would increase noninstrumental vaginal births in migrant women was not confirmed. Previous cohort studies conducted in the 
Table 3 Associations with labour and birth outcomes in nulliparous and parous women comparing migrant women with CBD support and Swedish born women

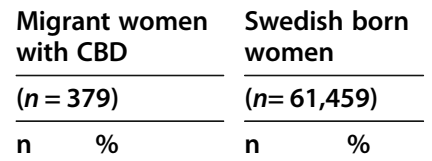

\section{$\operatorname{adjOR}^{\mathrm{a}} \mathrm{Cl}$} $95 \%$

\section{$\operatorname{adjOR}^{b} \mathrm{Cl}$} $95 \%$
$\operatorname{adjOR}^{c} \mathrm{Cl}$ $95 \%$

\section{Births to nulliparous women}

\section{Outcome}

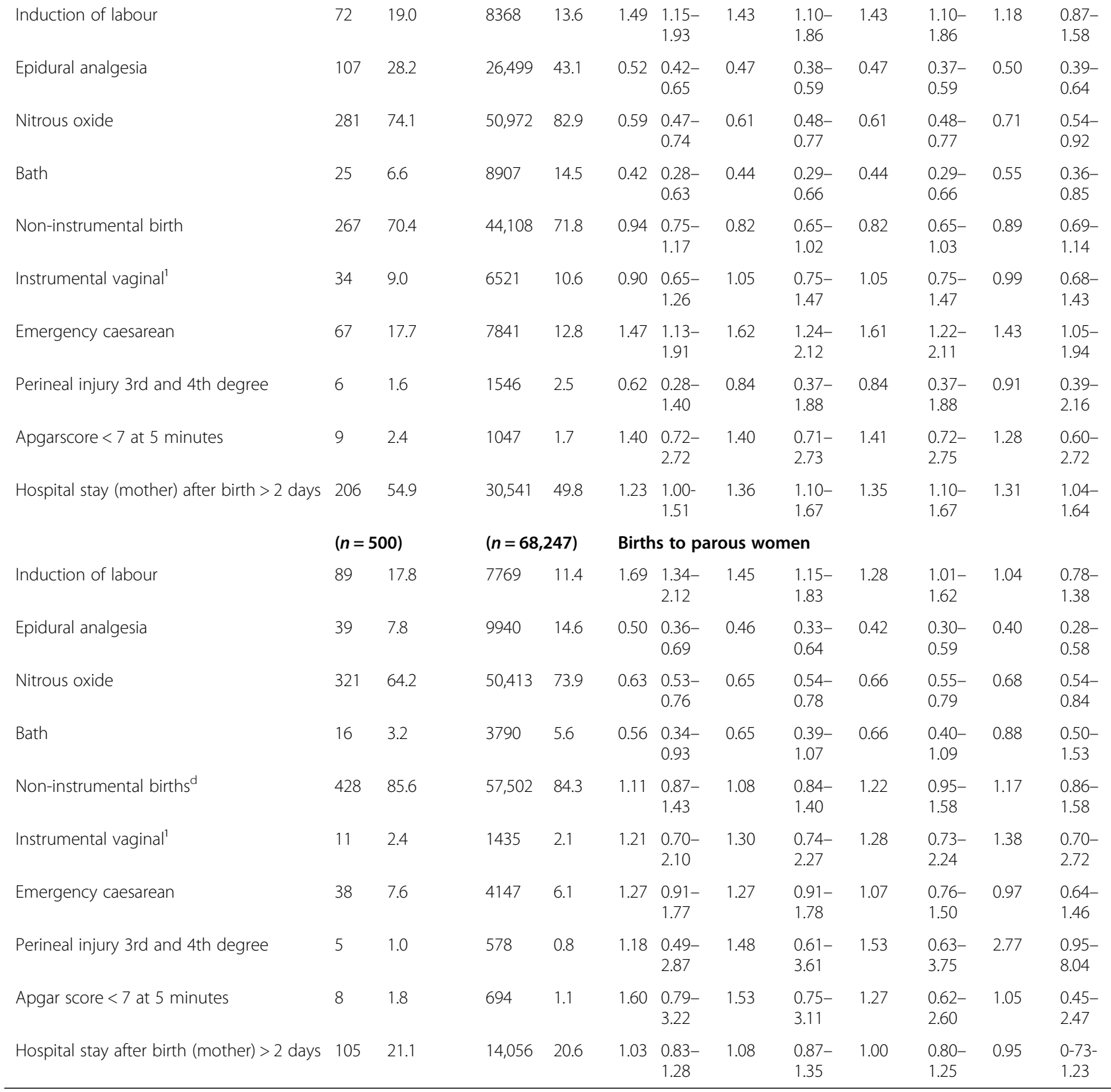


United States and the United Kingdom have indicated reduced likelihood of operative birth when doula support has been provided [8, 12, 14, 36, 37], however not consistently $[9,18,38]$. The reason our results did not demonstrate an increase in non-instrumental births may partly be due to differences in policies and "culture" regarding caesarean sections and non-instrumental vaginal births. With an overall caesarean section rate of $17 \%$, Sweden has a substantially lower rate [39] compared with the countries where previous studies were conducted; the United Kingdom 25-30\% [39], the United States 33\% [40], leaving less room to reduce caesarean sections further in the Swedish context by means of CBD support to migrant women. CBD support was associated in fact with increased odds of emergency caesarean section in nulliparous migrant women when compared with Swedish-born women, though not in parous women or when compared with migrant women without CBD support. This finding in nulliparous women might be interpreted as due to the increased risk of adverse pregnancy outcomes and poorer health particularly among women with refugee background [41] in spite of the adjustments made for some risks, or alternatively to improved communication and responses to women's need for, or wishes regarding intervention $[19,20]$.

Given that the migrant women who received $\mathrm{CBD}$ support constituted a socioeconomically and obstetrically vulnerable group (more single status, lower levels of education and income, refugee background and high BMI) [42], one might have expected higher odds of adverse birth outcomes in general within this group than in those without CBD support or in the Swedish-born women. The presence of a CBD strengthening communication between the woman and health professionals during labour as well as providing relaxation support, could be explanatory, as both these factors are linked to higher prevalence of non-instrumental vaginal birth $[7$, 43]. In light of this, offering CBD services to selected migrant women could be seen as an intervention addressing both inequalities in health and inequities in care, problems often highlighted in recent years [42, 44]. Our finding of more inductions of labour among migrant women with CBD support, and in particular among Somali-born women might suggest a similar mechanism. With the maternal characteristics reported in this study, and previously found adverse pregnancy outcomes within similar groups $[33,45]$, strengthened communication via a $\mathrm{CBD}$ may have better enabled adequate surveillance and timely decisions for intervention.

Comparing the birth outcomes in the current study with similar studies in different countries highlights the complexities of cross-country comparisons in the context of different health care structures and accessibility, as well as differing health outcomes. So far, most previous studies of CBD support have been conducted in the United States and a few in the United Kingdom. Additional RCTs investigating both women's experiences and obstetric outcomes are needed. To our knowledge, only one RCT is currently being conducted in a setting similar to the one presented here [2], however, the results of other ongoing intervention studies, albeit with other study designs and outcome measures in Norway [46], and Australia [47], will make valuable additions to the evidence base.

\section{Conclusions}

CBD support appears to have the potential to reduce analgesia use in migrant women with vulnerability to adverse outcomes, as in this study. It may also be that some necessary interventions were facilitated by the enhanced communication made possible by the presence of a CBD. Further studies of the effect of CBD support on mode of birth and other obstetric outcomes as well as on migrant women's experiences and well-being are needed.

\section{Abbreviations \\ CBD: Community-based Bilingual Doula; MBR: The Swedish Medical Birth Register; SCB: Statistics Sweden; aOR: Adjusted odds ratio; Cl: Confidence intervals}

\section{Acknowledgements}

The authors wish to express their gratitude to Födelsehuset/Mammaforum Gothenburg who have provided support over many years to childbearing women. We thank them for their kind collaboration during the data retrieval phase of this study.

\section{Authors' contributions}

ES and RS initiated the study. ES, UB and RS contributed to planning and design. ES and UB prepared the data set and UB performed the statistical analyses. All authors interpreted the results. UB drafted the manuscript and ES, RS and UB revised it. All authors read and approved the final manuscript.

\section{Funding}

This study has received funding from the Swedish Research Council [grant number 2015-02470], Forte [grant number 2016 - 00957] and Region Stockholm. The funding bodies have played no role in the design of the study, nor in data collection, analysis and interpretation of the data or in writing the manuscript. Open Access funding provided by Högskolan Dalarna.

\section{Availability of data and materials}

The data sets generated and analysed during the current study are not publicly available due to confidentiality regulations, but may be available from the corresponding author on reasonable request.

\section{Ethics approval and consent to participate}

The study is approved by the Regional Ethical Review Board, Stockholm, Sweden, 2017-08-08, Dnr 2017/323. Administrative permissions were approved by the respective register holders; Statistics Sweden, The Swedish Medical Birth Register and Födelsehuset/Mammaforum.

Consent for publication

No individual data can be identified in the manuscript.

Competing interests

The authors declare that they have no competing interests. 


\section{Author details}

${ }^{1}$ School of Education, Health and Social Sciences, Dalarna University, Falun, Sweden. ${ }^{2}$ Judith Lumley Centre, La Trobe University, 3086 Melbourne, Victoria, Australia. ${ }^{3}$ Division of Reproductive Health, Department of Women's and Children's Health, Karolinska Institutet, Tomtebodavägen 18a, 17177 Stockholm, Sweden. ${ }^{4}$ Centre for Clinical Research Dalarna, Uppsala University, Nissers väg 3, 79182 Falun, Sweden. ${ }^{5}$ Faculty of Health and Social Sciences, Western Norway University of Applied Sciences, Møllendalsveien 6, Postboks 7030, 5020 Bergen, Norway.

Received: 1 July 2020 Accepted: 12 November 2020 Published online: 23 November 2020

\section{References}

1. Small R, Roth C, Raval M, Shafiei T, Korfker D, Heaman M, et al. Immigrant and non-immigrant women's experiences of maternity care: a systematic and comparative review of studies in five countries. BMC Pregnancy Childbirth. 2014;14:152

2. Schytt E, Wahlberg A, Eltayb A, Small R, Tsekhmestruk N, Lindgren $\mathrm{H}$. Community-based doula support for migrant women during labour and birth: study protocol for a randomised controlled trial in Stockholm, Sweden (NCT03461640). BMJ open. 2020;10(2):e031290.

3. Gagnon AJ, Zimbeck M, Zeitlin J, Collaboration R, Alexander S, Blondel B, et al. Migration to western industrialised countries and perinatal health: a systematic review. Soc Sci Med. 2009;69(6):934-46.

4. Urquia ML, Glazier RH, Blondel B, Zeitlin J, Gissler M, Macfarlane A, et al. International migration and adverse birth outcomes: role of ethnicity, region of origin and destination. J Epidemiol Community Health. 2010;64(3):243-51.

5. Juarez SP, Small R, Hjern A, Schytt E. Caesarean Birth is Associated with Both Maternal and Paternal Origin in Immigrants in Sweden: a Population-Based Study. Paediatr Perinat Epidemiol. 2017;31(6):509-21.

6. Vik ES, Nilsen RM, Aasheim V, Small R, Moster D, Schytt E. Country of first birth and neonatal outcomes in migrant and Norwegian-born parous women in Norway: a population-based study. BMC Health Serv Res. 2020; 20(1):540.

7. Bohren MA, Hofmeyr GJ, Sakala C, Fukuzawa RK, Cuthbert A. Continuous support for women during childbirth. Cochrane Database Syst Rev. 2017;7: Cd003766.

8. Dundek LH. Establishment of a Somali doula program at a large metropolitan hospital. J Perinat Neonatal Nurs. 2006;20(2):128-37.

9. Mottl-Santiago J, Walker C, Ewan J, Vragovic O, Winder S, Stubblefield P. A hospital-based doula program and childbirth outcomes in an urban, multicultural setting. Matern Child Health J. 2008;12(3):372-7.

10. McLeish J, Redshaw M. "Being the best person that they can be and the best mum": a qualitative study of community volunteer doula support for disadvantaged mothers before and after birth in England. BMC Pregnancy Childbirth. 2019;19(1):21.

11. Wint K, Elias TI, Mendez G, Mendez DD, Gary-Webb TL. Experiences of Community Doulas Working with Low-Income, African American Mothers. Health equity. 2019;3(1):109-16.

12. Kozhimannil KB, Hardeman RR, Attanasio LB, Blauer-Peterson C, O'Brien M. Doula care, birth outcomes, and costs among Medicaid beneficiaries. American journal of public health. 2013;103(4):e113-21.

13. Steel A, Frawley J, Adams J, Diezel H. Trained or professional doulas in the support and care of pregnant and birthing women: a critical integrative review. Health Soc Care Commun. 2015;23(3):225-41.

14. McGrath SK, Kennell JH. A randomized controlled trial of continuous labor support for middle-class couples: effect on cesarean delivery rates. Birth. 2008;35(2):92-7.

15. Lanning RK, Oermann MH, Waldrop J, Brown LG, Thompson JA. Doulas in the Operating Room: An Innovative Approach to Supporting Skin-to-Skin Care During Cesarean Birth. J Midwifery Women Health. 2019;64(1):112-7.

16. Kozhimannil KB, Attanasio LB, Jou J, Joarnt LK, Johnson PJ, Gjerdingen DK. Potential benefits of increased access to doula support during childbirth. Am J Manag Care. 2014;20(8):e340-52

17. Bohren MA, Hofmeyr GJ, Sakala C, Fukuzawa RK, Cuthbert A. Continuous support for women during childbirth. Cochrane Database Syst Rev. 2017; 7(7):Cd003766

18. Campbell DA, Lake MF, Falk M, Backstrand JR. A randomized control trial of continuous support in labor by a lay doula. Journal of obstetric, gynecologic, and neonatal nursing. JOGNN. 2006;35(4):456-64.
19. Akhavan S, Edge D. Foreign-born women's experiences of CommunityBased Doulas in Sweden - a qualitative study. Health Care Women Int. 2012; 33(9):833-48.

20. Akhavan S, Lundgren I. Midwives' experiences of doula support for immigrant women in Sweden - a qualitative study. Midwifery. 2012;28(1):80-5.

21. The Swedish Society of Obstetrics and Gynecology (SFOG). and The Swedish Association of Midwives. Modrahalsovard, Sexuell och Reproduktiv Halsa. ARG report 76. Stockholm; 2016.

22. Statistics Sweden. (Statistiska Centralbyrån). Statistical Database. http://www. ssd.scb.se/ Accessed 20 Feb 2014.

23. Swedish National Board of Health and Welfare (Socialstyrelsen). Graviditeter, förlossningar och nyfödda barn. Medicinska födelseregistret 1973-2011. Assisterad befruktning 1991-2010. Stockholm: Socialstyr.; 2013. 48 p.

24. Doula \& kulturtolk Göteborg. 2019 [Available from: https://www. doulakulturtolk.se/goteborg/.

25. Swedish National. Board of Health and Welfare (Socialstyrelsen). Medicinska Födelseregistret 2019.

26. Statistics Sweden. (Statistiska Centralbyrån) 2018.

27. Källén B, Källén K, Lund U, Tornbladinstitutet, Tornblad I. The Swedish Medical Birth Register - a summary of content and quality 2003. Lunds University, Sweden.

28. Cnattingius S, Ericson A, Gunnarskog J, Kallen B. A quality study of a medical birth registry. Scand J Soc Med. 1990;18(2):143-8.

29. Statistics Sweden. Statistiska centralbyråns föreskrifter om utvärdering av den officiella statistikens kvalitet; SCB-FS 2017:8, SCB-FS 2017:8 (2017).

30. Institute for Health Metrics and Evaluation. Compare GBD: University of Washington; 2017 https://vizhub.healthdata.org/gbd-compare/ Accessed 15 Oct 2019.

31. Hodnett ED, Gates S, Hofmeyr GJ, Sakala C. Continuous support for women during childbirth. Cochrane Database Syst Rev. 2013;7:Cd003766.

32. Ekéus C, Cnattingius S, Hjern A. Epidural analgesia during labor among immigrant women in Sweden. Acta obstetricia et gynecologica Scandinavica. 2010;89(2):243-9.

33. Råssjö EB, Byrskog U, Samir R, Klingberg-Allvin M. Somali women's use of maternity health services and the outcome of their pregnancies: a descriptive study comparing Somali immigrants with native-born Swedish women. Sexual reproductive healthcare. 2013;4(3):99-106.

34. Aasheim V, Nilsen RM, Skirnisdottir Vik E, Small R, Schytt E. Epidural analgesia for labour pain in nulliparous women in Norway in relation to maternal country of birth and migration related factors. Sexual Reproductive Healthcare. 2020;26:1005532.

35. Waldum Henning $\AA$, Flem Jacobsen A, Lukasse M, Staff AC, Sørum Falk R, Vangen S. Krarup Sørbye I. The provision of epidural analgesia during labor according to maternal birthplace: a Norwegian register study. BMC Pregnancy and Childbirth. 2020; 20;321.

36. Kozhimannil KB, Hardeman RR, Alarid-Escudero F, Vogelsang CA, BlauerPeterson C, Howell EA. Modeling the Cost-Effectiveness of Doula Care Associated with Reductions in Preterm Birth and Cesarean Delivery. Birth (Berkeley Calif). 2016;43(1):20-7.

37. Goedkoop V. Side by side - a survey of doula care in the UK in 2008. MIDRIS Midwifery Digest. 2009;19:217-9.

38. Thomas M-P, Ammann G, Brazier E, Noyes P, Maybank A. Doula Services Within a Healthy Start Program: Increasing Access for an Underserved Population. Matern Child Health J. 2017;21(1):59-64.

39. Macfarlane A, Blondel B, Mohangoo A, Cuttini M, Nijhuis J, Novak Z, et al. Wide differences in mode of delivery within Europe: risk-stratified analyses of aggregated routine data from the Euro-Peristat study. BJOG: An International Journal of Obstetrics Gynaecology. 2016;123(4):559-68.

40. Betrán AP, Ye J, Moller A-B, Zhang J, Gülmezoglu AM, Torloni MR. The Increasing Trend in Caesarean Section Rates: Global, Regional and National Estimates: 1990-2014. PLOS ONE. 2016;11(2):e0148343.

41. Bakken KS, Skjeldal OH, Stray-Pedersen B. Immigrants from conflict-zone countries: an observational comparison study of obstetric outcomes in a low-risk maternity ward in Norway. BMC Pregnancy Childbirth. 2015;15:163.

42. Heslehurst N, Brown H, Pemu A, Coleman H, Rankin J. Perinatal health outcomes and care among asylum seekers and refugees: a systematic review of systematic reviews. BMC Med. 2018;16(1):89.

43. Sentell T, Chang A, Ahn HJ, Miyamura J. Maternal language and adverse birth outcomes in a statewide analysis. Women Health. 2016;56(3):257-80.

44. Socialstyrelsen. Öppna jämförelser jämlik vård 2016. Kvinnors hälso-och sjukvård fördjupningsrapport. 2016. 
45. Small R, Gagnon A, Gissler M, Zeitlin J, Bennis M, Glazier R, et al. Somali women and their pregnancy outcomes postmigration: data from six receiving countries. BJOG: an international journal of obstetrics gynaecology. 2008;115(13):1630-40

46. Haugaard A, Larsson Tvedte S, Stene Severinsen M, Henriksen L. Norwegian multicultural doulas' experiences of supporting newly-arrived migrant women during pregnancy and childbirth: A qualitative study. Sexual Reproductive Healthcare. 2020;26:100540,

47. O'Rourke M, Yelland J, Newton M, Shafiei T. An Australian doula program for socially disadvantaged women: Developing realist evaluation theories. Women Birth. 2020;22:e438-46.

\section{Publisher's Note}

Springer Nature remains neutral with regard to jurisdictional claims in published maps and institutional affiliations.

Ready to submit your research? Choose BMC and benefit from:

- fast, convenient online submission

- thorough peer review by experienced researchers in your field

- rapid publication on acceptance

- support for research data, including large and complex data types

- gold Open Access which fosters wider collaboration and increased citations

- maximum visibility for your research: over $100 \mathrm{M}$ website views per year

At BMC, research is always in progress.

Learn more biomedcentral.com/submissions 